DOI: http://dx.doi.org/10.22201/iie.18703062e.2006.89.2220

\author{
VERÓNICA HERNÁNDEZ DÍAZ
}

\title{
Los janamus grabados de Tzintzuntzan, Michoacán
}

A mi siempre muy querida maestra,

Beatriz de la Fuente

\section{Un arte prehispánico y virreinal}

$\mathrm{E}$ n Tzintzuntzan, Michoacán, la antigua capital del imperio tarasco, se encuentra un caso excepcional de reutilización de piezas arquitectónicas de origen prehispánico en construcciones virreinales. Se trata de losas, llamadas janamus — en purépecha_- que fueron empotradas tanto en las pirámides de la zona arqueológica como en el convento franciscano de la localidad. Son piedras de basalto pulidas y cortadas con precisión en ángulos rectos y formas rectangulares, cuyas medidas promedio en centímetros son de $45 \times 32$ y el espesor aproximado es de I5. Algunos janamus tienen imágenes grabadas o en bajorrelieve y la mayoría son geométricas, como espirales de varios tipos y círculos combinados con líneas diversas. Apenas unos cuantos muestran diseños de apariencia humana; entre ellos hay uno que destaca especialmente, pues la losa donde se plasmó está colocada de manera horizontal, pero la composición de la imagen es vertical (fig. I). Vista así, la figura se aprecia sentada, con el cuerpo de perfil y encorvado, y las piernas dobladas hacia arriba; apoya sus codos sobre las rodillas, y con las manos sostiene un objeto alargado, que casi alcanza la boca; la cabeza de la figura está de frente, los ojos y la boca son formas circulares ahuecadas, tiene apéndices o antenas largas que se curvan hacia abajo. 
Es factible reconocer este diseño como un "Flautista". Tal es el nombre que recibe un personaje mítico y sagrado característico de las culturas indígenas del

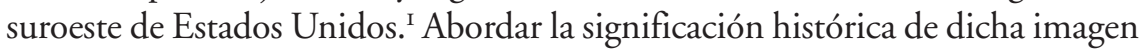
en Michoacán nos conduce por distantes migraciones y retornos emprendidos por los purépechas, la etnia dirigente del Estado tarasco.

Conviene hacer una aclaración antes de seguir con el tema. Con el propósito de abordar de modo más preciso la complejidad de los sucesos implícitos, daré un empleo distinto a las palabras tarasco y purépecha. Por tarasco me referiré al grupo pluriétnico que conformó al Estado tarasco después del año I300, durante el Posclásico tardío. ${ }^{2}$ Purépecha será el nombre dado a la gente de esta etnia que consolidó a dicha organización sociopolítica y constituyó su elite dirigente.

En este trabajo, se exponen consideraciones sobre el conjunto de los janamus decorados y el Flautista en particular. ${ }^{3}$ Consiste en un tema inédito, aun cuando los monumentos prehispánicos y virreinales de Tzintzuntzan han sido estudiados desde antaño. Sucede que a la fecha las investigaciones arqueológicas sólo habían mencionado brevemente la presencia de lajas grabadas en las pirámides o en sus restos, y por su parte los estudiosos del arte virreinal no habían reparado en su integración en los muros del convento de San Francisco. De tal suerte, el repertorio de estas obras no había sido analizado; en ningún caso previo se abunda sobre el tema y tampoco conocí reporte gráfico o descripción extensa de los petrograbados. ${ }^{4}$

I. Popularmente se conoce como Kokopelli; en este artículo no se emplea tal nombre, puesto que se aplica sólo a una kachina particular; en tanto, el vocablo Flautista es genérico y tiene connotaciones más amplias.

2. Comprendía grupos mazahuas, otomíes, nahuas, chontales, apanecas, cuitlatecos (Ulises Beltrán, "Estado y sociedad tarascos en la época prehispánica", en Brigitte Boehm de Lameiras (coord.), El Michoacán antiguo, Zamora, Michoacán, Gobierno del Estado de Michoacán-El Colegio de Michoacán, 1994, pp. 3I-I63).

3. El origen del presente registro y análisis se remonta a marzo de 2000 , cuando hice la identificación del Flautista en Tzintzuntzan.

4. La revisión historiográfica que hice de las investigaciones arqueológicas en torno al pasado prehispánico y los estudios histórico-artísticos sobre la arquitectura virreinal en Michoacán, pueden consultarse en: Verónica Hernández Díaz, "Los janamus grabados en la arquitectura prehispánica y virreinal de Tzintzuntzan, Michoacán”, tesis de maestría en Historia del Arte, México, Universidad Nacional Autónoma de México-Facultad de Filosofía y Letras, 2006. Cabe ahora destacar a Joseph B. Mountjoy, quien en 1970 y 197I registró gráficamente y de modo esquemático 45 petrograbados en la zona arqueológica y el convento franciscano de Tzintzuntzan; en su publicación dedica algunos párrafos al tema: Some Hyphotesis Regarding the Petroglyphs of 
I. Janamu con el diseño del Flautista. La losa está empotrada de modo horizontal. Capilla de hospital, convento de San Francisco, Tzintzuntzan, Michoacán. Foto: V. H.

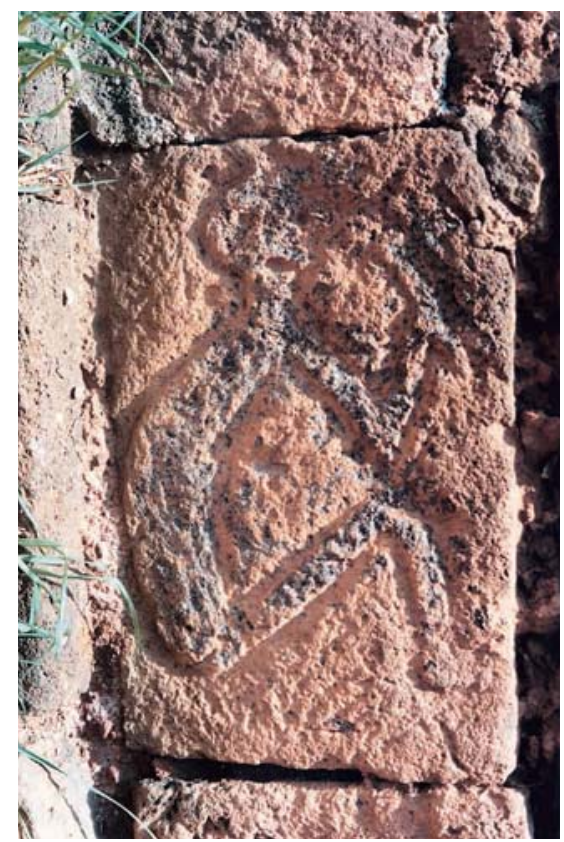

Entre otros asuntos, el descubrimiento del Flautista en Tzintzuntzan me permitió iniciar un estudio sobre las influencias en territorio michoacano de culturas norteñas y del extenso fenómeno de "toltequización" que experimentó Mesoamérica, un tema complejo que en relación con los tarascos ha sido poco tratado. 5 Dicha figura se suma a otras creaciones artísticas, como el chacmool y la sala de columnas, que ponen en evidencia una complicada red de intercambios manifestados en el legado prehispánico en Michoacán. En el desarrollo de la investigación ha sido oportuno contar con las indagaciones de Patricia Carot y Marie-Areti Hers acerca de una antigüedad mayor en la historia purépecha y sus lazos con las culturas hohokam y chalchihuiteña.

En su faceta como arte indígena virreinal, el empleo de los janamus grabados en la arquitectura franciscana tuvo lugar desde el siglo XVI hasta el XVIII; lo atestiguan así las características estilísticas de los monumentos y algunas fuentes

West Mexico, Mesoamerican Studies, núm. 9, Carbondale, University Museum, Southern Illinois University of Carbondale, 1974, pp. I8, 19, figs. 9 y 10.

5. Hernández Díaz, op. cit. 


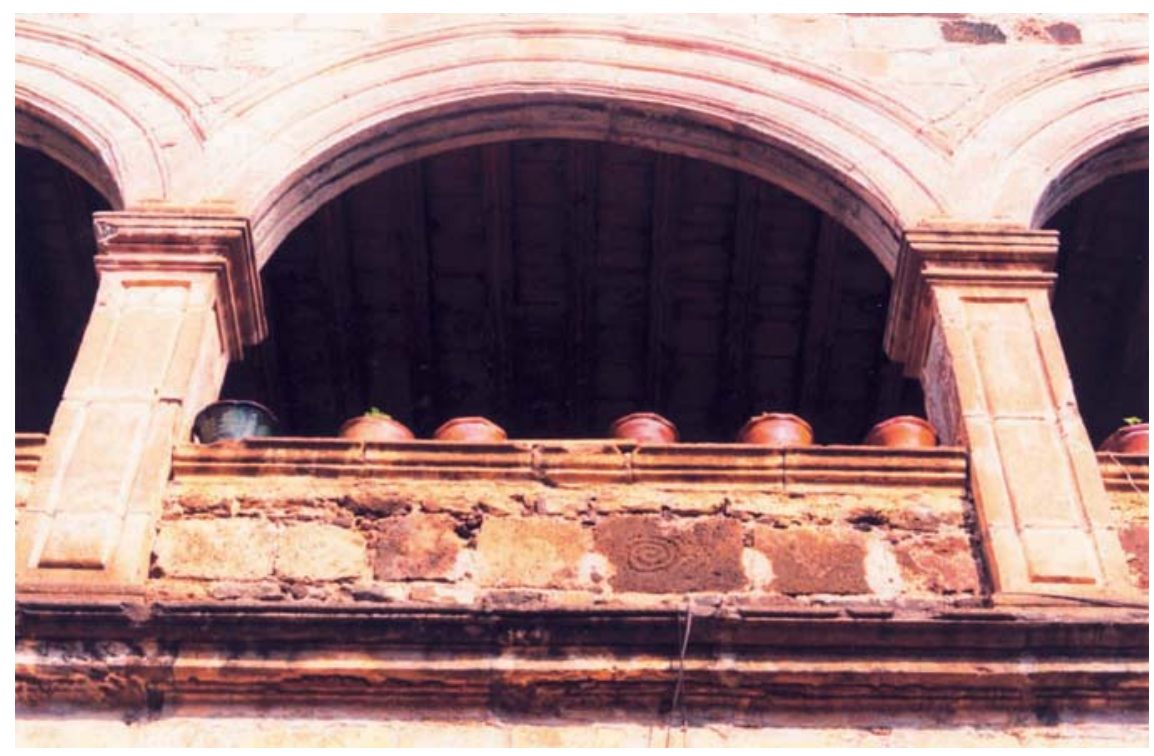

2. Janamu con una espiral. Claustro del convento de San Francisco, Tzintzuntzan, Michoacán. Foto: V. H.

que refieren la temporalidad de su construcción. Resulta extraordinario este prolongado reúso de obras prehispánicas en los edificios novohispanos, ajenos a las tradiciones mesoamericanas, aunque sin duda fueron realizados por manos tarascas, si bien en plena cooperación con los frailes y dentro de las tareas de evangelización, por lo cual se insinúa la cuestión del sincretismo.

La participación de los tarascos en el convento de Tzintzuntzan no sólo puede identificarse en los materiales, las técnicas y el estilo, sino también en la expresión de sus conceptos y símbolos, de una manera tan directa como fue la incorporación, en esta nueva arquitectura religiosa, de las mismas piedras con imágenes que antes decoraban las pirámides de su centro ceremonial antiguo (fig. 2). Este hecho y otros indicios que han resultado en la investigación me llevan a distinguir los profundos significados que pudieron tener estas obras para sus creadores, de ahí que infiera su intencionada reutilización por parte de los tarascos, en particular de su elite purépecha, en tanto formas de expresión plástica propia del periodo prehispánico y colonial de Tzintzuntzan. 
3. Mapa con algunos sitios referidos

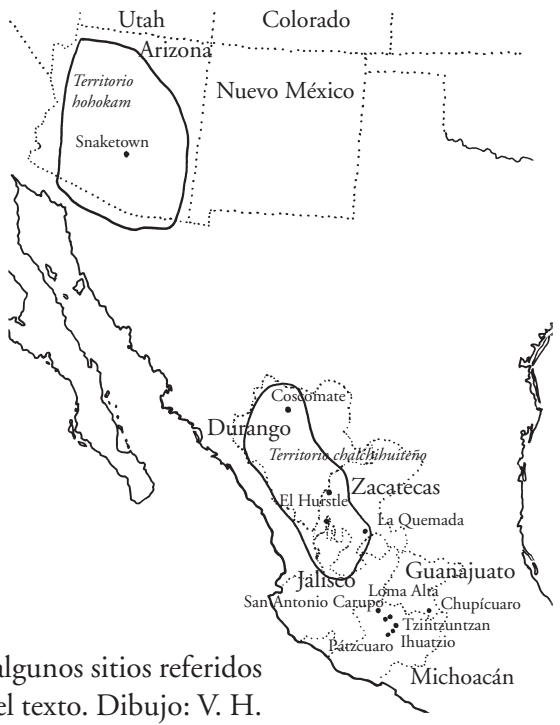

\section{La arquitectura, los janamus y sus imágenes}

Durante los dos siglos anteriores a la conquista, los tarascos constituyeron una de las culturas más importantes de Mesoamérica. ${ }^{6}$ La ciudad de Tzintzuntzan era su capital a la llegada de los españoles (fig. 3); se localiza en la ribera oriental del lago de Pátzcuaro y desde el año 1350 se convirtió en el mayor asentamiento de dicho pueblo. El núcleo de su principal recinto ceremonial es actualmente la zona arqueológica de Tztintzuntzan (fig. 4). ${ }^{7}$ Sobre una gran plataforma artificial destacan alineadas cinco pirámides o yácatas, las cuales están construidas con varias superposiciones de piedra y comparten un solo basamento. La planta de las yácatas es mixta, combina una forma rectangular con otra semicircular. Por la Relación de Michocán suponemos que estaban dedicadas a la suprema deidad tarasca, Curicaueri, un dios solar y del fuego. ${ }^{8}$ Ahí se realizaban rituales

6. En la etapa de apogeo el dominio tarasco abarcó la mayor parte del actual territorio de Michoacán y partes colindantes con Jalisco, Guanajuato y Guerrero.

7. Helen P. Pollard, Taríacuri's Legacy. Prehispanic Tarascan State, Norman, University of Oklahoma Press, 1993, p. 29.

8. El título completo de este documento es Relación de las ceremonias y ritos y población y gobernación de los indios de la provincia de Michoacán. Su autoría y compilación se atribuyen 
de suma relevancia, como la cremación y sepultura del cazonci, sacrificios humanos, entierros de las elites gobernantes, oraciones previas a acciones de guerra y encendido de hogueras en honor a Curicaueri. Puesto que el uso de los janamus grabados en el revestimiento de los edificios no fue exclusivo de Tzintzuntzan, cabe decir que este rasgo caracteriza la arquitectura tarasca. ${ }^{9}$

Al pie de la colina donde se asienta la zona arqueológica de Tzintzuntzan está ubicado el convento de San Francisco; su establecimiento data desde el siglo XvI y con el tiempo llegó a conformar un conjunto monumental. Está delimitado por una barda ancha de piedra, las construcciones que lo integran son de piedra y se disponen en dos atrios. En el principal, y de mayores dimensiones, existen pequeñas ermitas para la celebración del Vía Crucis, una cruz atrial, la antigua sede del monasterio, la capilla abierta de San Camilo, las iglesias de San Francisco y de la Virgen de la Soledad, la residencia actual de los frailes, una portada aislada y numerosos olivos. La capilla de hospital es el edificio más importante del segundo atrio, ahí se ven también una cruz atrial, una pila bautismal y la fachada lateral del templo de la Soledad. Los edificios virreinales del convento datan desde la década de $157 \mathrm{O}^{10}$ hasta 1805 , año inscrito en el remate del segundo cuerpo del templo de la Virgen de la Soledad.

En el registro efectuado en mayo del año 2000 en las yácatas de la zona arqueológica y en el convento franciscano de Tzintzuntzan, encontré 52 lajas grabadas; la posterior indagación bibliográfica me permitió agregar seis a las diez observadas en las pirámides. ${ }^{\mathrm{II}}$ De este modo, del total de 58 janamus, $\mathrm{I} 6$ corresponden a las yácatas y 42 al convento.

al franciscano Jerónimo de Alcalá; fue elaborada en Tzintzuntzan entre 1539 y 1543 (Francisco Miranda, "Estudio preliminar", en fray Jerónimo de Alcalá, La Relación de Michoacán, Morelia, Fímax Publicistas, 1980, p. 20).

9. También he advertido el uso superficial de losas decoradas en edificios de las antiguas capitales de Pátzcuaro e Ihuatzio, asimismo en sitios de jerarquía menor, como Huandacareo, y en otro que data del Posclásico temprano llamado San Antonio Carupo.

Io. Para apuntar esta fecha me baso en varias crónicas coloniales, en los estudios de investigadores como John McAndrew (The Open-air Churches of Sixteenth Century, Mexico. Atrio, Posas, Open Chapels, and other Studies, Cambridge, Harvard University Press, 1965), Manuel Toussaint (Pátzcuaro, México, Universidad Nacional Autónoma de México-Instituto de Investigaciones Estéticas/Escuela de Arquitectura, 1942), y George Kubler (Arquitectura mexicana del siglo XVI, 1948, México, Fondo de Cultura Económica, 1992); y en documentos de la época virreinal (véase Carlos Paredes Martínez (ed.), Y por mi visto... Mandamientos, ordenanzas, licencias y otras disposiciones virreinales sobre Michoacán en el siglo XVI, México, Centro de Investigaciones y Estudios Superiores en Antropología Social/Universidad Michoacana de San Nicolás de Hidalgo, 1995).

II. En las yácatas observé dos petrograbados más que no tomo en cuenta. De uno sólo anoté 


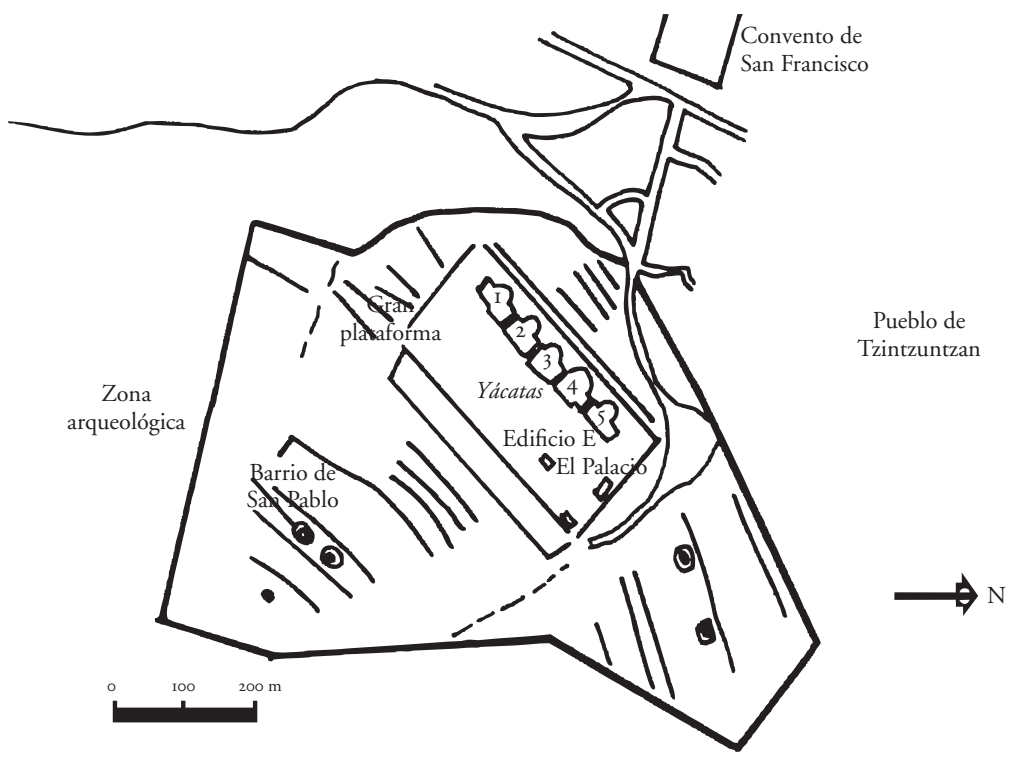

4. Plano de la zona arqueológica de Tzintzuntzan, Michoacán. Dibujo: V. H., basado en Efraín Cárdenas García, "Pátzcuaro, Ihuatzio y Tzintzuntzan”, Arqueología Mexicana, México, Instituto Nacional de Antropología e Historia/Raíces, vol. IV, núm. I9, I996, p. 3 I.

Casi es un hecho que la cantidad sea mayor, debido a que la exploración sólo tuvo lugar en partes abiertas al público en general y en los dos sitios hay áreas restringidas. ${ }^{\mathrm{I2}}$ Además, en el espacio franciscano es posible que algunas

sus medidas y localización; sin embargo, no lo dibujé ni fotografié; en el restante se ve una figura humana, pero su manufactura parece reciente, por lo que tampoco es considerado. En la zona arqueológica encontré otra construcción con un janamu grabado. Se trata de la Estructura E, próxima a las yácatas en dirección oriente; consta de varios cuartos alineados y en uno de sus muros se ve una espiral.

Respecto a los seis janamus que localicé por medio de publicaciones, la fuente principal es: Jorge R. Acosta, "Exploraciones arqueológicas realizadas en el estado de Michoacán durante los años de 1937 y 1938”, Revista Mexicana de Estudios Antropológicos, México, Sociedad Mexicana de Antropología, t. III, núm. 2, mayo-agosto de 1939, pp. 85-98. Este arqueólogo incluye el dibujo de cuatro janamus decorados y las fotos de tres más (todos se ven exentos); cinco de ellos aumentan el repertorio conocido.

I2. En la zona arqueológica está prohibido el ascenso a las yácatas y sólo una parte menor de las estructuras ha sido liberada, de ahí que el área donde se permite el ingreso público es reducida. En el caso del conjunto franciscano, está bloqueada la sección sur del convento y no se me autorizó subir al piso superior del claustro. 


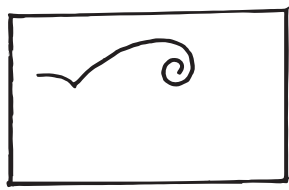

a)

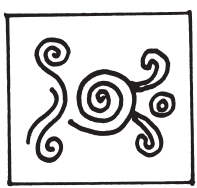

b)

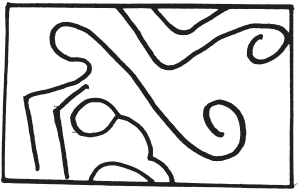

c)

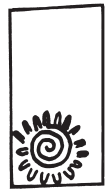

d)

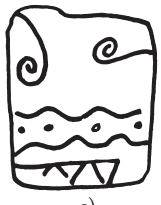

e)

5. Variedad de diseños y de su distribución en la superficie de los janamus grabados presentes en la arquitectura prehispánica y virreinal de Tzintzuntzan, Michoacán (los dibujos de los janamus no presentan medidas proporcionales entre sí). Dibujos: V. H.

porciones del enlucido de sus muros cubran otras imágenes grabadas. Es probable asimismo que una gran cantidad se halle dispersa, ya que en 1937-1938, cuando se practicaron las primeras excavaciones arqueológicas, las yácatas estaban muy deterioradas a causa del saqueo de materiales para construcción y de la búsqueda de tesoros. ${ }^{13}$ En consecuencia, la mayor parte de los janamus grabados que revisten actualmente las yácatas no se encuentran en su posición original. Ello se debe a que fue necesario rehacerlas, no obstante sí se comprobó su asociación directa: el hallazgo arqueológico de janamus decorados entre los escombros superficiales de las yácatas hizo suponer que recubrían los monumentos, lo cual quedó en evidencia en la segunda temporada, cuando algunos se descubrieron in situ. ${ }^{\mathrm{I}}$

En términos amplios, sobre las yácatas destaca que la número dos no está asociada con algún janamu decorado. Al parecer, a la número cinco, la que mejor conservó su estado original, se le puede atribuir la mayor cantidad de losas decoradas, las cuales sumarían seis (el número tentativo se debe a que la información bibliográfica no es del todo precisa). Aunque conviene enfatizar que de las cinco yácatas no es posible decir cuál tenía originalmente más janamus grabados debido al estado en que se encontraron antes de la reconstrucción arqueológica.

La ornamentación de todos los janamus es variada. En ocasiones se trata de un solo motivo, ya sea sencillo o elaborado; en otras se ven diseños separados.

13. Marcia Castro Leal, Tzintzuntzan, capital de los tarascos, Morelia, Gobierno del Estado de Michoacán, 1986, pp. 3I-48; Acosta, op. cit., pp. 85 y 86.

I4. Ibidem, pp. 88, 89. Además de los registrados por Jorge R. Acosta, en sus trabajos arqueológicos, Rubén Cabrera encontró en su lugar original —la yácata 3- algunos janamus grabados. Apunta que las formas son geométricas y antropomorfas, sin embargo en su publicación sólo incluye el dibujo de una: "Tzintzuntzan, décima temporada de excavaciones", en Barbro Dahlgren et al. (organizadores), Homenaje a Román Piña Chan, México, Universidad Nacional Autónoma de México-Instituto de Investigaciones Antropológicas, 1987, pp. 531-565. 

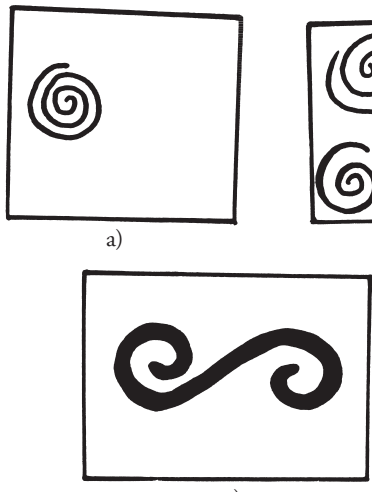

e)

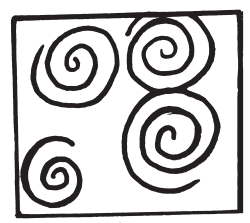

b)

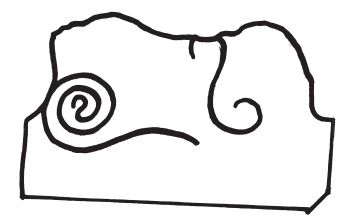

c)

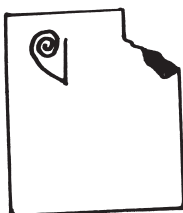

d)

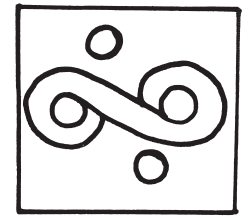

f)

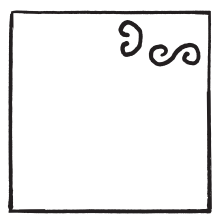

g)

6. Janamus decorados de la arquitectura de Tzintzuntzan, Michoacán. Distintas modalidades del diseño de las espirales: a) simple; b) alineada; c) con vuelta interior particular; d) con vuelta exterior particular; e) doble divergente; f) doble divergente con círculos; g) doble convergente y divergente. Dibujos: V. H.

Respecto a su distribución, se pueden ver en el centro, hacia las esquinas o los extremos, abarcando buena parte de la superficie o una sección pequeña de la losa (fig. 5). La mayoría de los diseños no son figurativos sino abstractos, de acuerdo a nuestra percepción cultural. Las categorías formales básicas que resultaron a partir de su clasificación son: espiral, círculo, líneas onduladas alargadas, reticulado, geométrico-figurativo (flor, estrella, letra A) y antropomorfo. A su vez, en algunas de las categorías se perciben variantes, por ejemplo, en el caso de los círculos las cuatro modalidades son: sencilla, concéntrica, asociada con líneas rectas y asociada con líneas curvas.

Las espirales son las formas que presentan mayor diversidad visual: se pueden ver simples (fig. 6a), alineadas (fig. 6b), con vuelta interior (fig. 6c) o exterior particular (fig. 6d), radiadas, con líneas curvas, con líneas combinadas, dobles divergentes (fig. 6e) (similar a una $S$; es un motivo que en náhuatl se nombra xonecuilli), dobles divergentes con líneas rectas, dobles divergentes radiadas, dobles divergentes con círculos (fig. 6f), dobles divergentes y convergentes (fig. 6g), y convergentes.

En términos numéricos, en los 58 janamus que registré el diseño más frecuente es la espiral sencilla ( 17 veces), grabada en forma individual, alineada, con vuelta interior o exterior particular, radiada o combinada con líneas rectas y curvas. Le siguen la espiral doble divergente ( $\mathrm{I} 3$ veces), el círculo (diez veces) 
—entre cuyas representaciones sobresalen los concéntricos-, las líneas alargadas onduladas (cuatro veces), el motivo geométrico-figurativo flor (tres veces), el antropomorfo (tres veces), el geométrico-figurativo estrella (dos veces); la espiral doble divergente y convergente (dos veces), la espiral doble convergente (dos veces), el reticulado (una vez) y el geométrico figurativo letra (una vez).

De los diseños plasmados en los janamus en las yácatas, I5 son geométricoabstractos y en uno se figura un humano de modo esquemático. El motivo más frecuente es la espiral doble divergente, presente en siete janamus.

Acerca de las 42 losas decoradas que registré en el convento franciscano, i8 se encuentran en un solo edificio, la capilla de hospital. El diseño más frecuente en ambos casos, el convento y dicha capilla, es la espiral simple, grabada en distintas modalidades.

Las formas observadas en las yácatas se ven también en este recinto religioso, por ejemplo, espirales sencillas, círculos concéntricos, espirales dobles divergentes, espirales dobles divergentes y convergentes, líneas onduladas y antropomorfos lineales.

Con base en el análisis formal de los janamus decorados y en el marco histórico de su realización prehispánica y de su reúso durante el virreinato, se distingue que casi la totalidad de los janamus empotrados en los edificios novohispanos provienen de la arquitectura prehispánica. No es seguro que procedan exclusivamente de las yácatas de la cercana zona arqueológica, en tanto se considera la extensión de la capital tarasca al arribo de los españoles, y por ende, el gran número de construcciones que existía. Es conocido que las obras de los conquistadores fueron erigidas con suma frecuencia de modo directo sobre las edificaciones indígenas, de ahí que aprovecharan sus materiales. En el caso de Tzintzuntzan, janamus antiguos sirvieron para revestir los nuevos muros cristianos, aunque se desconoce si estaban a la vista o cubiertos con enlucido. ${ }^{\text {Is }}$

\section{La capilla de hospital: entre la tradición y el cambio}

En el convento franciscano la capilla de hospital es notable por contar con el mayor número de janamus grabados: 18 , casi la mitad del total registrado. Se trata de un edificio abierto y de dimensiones pequeñas. Tal abundancia en el

I5. Actualmente algunos edificios conservan restos de enlucido, otros, como la capilla de hospital y los muros del atrio, tienen la piedra expuesta. 


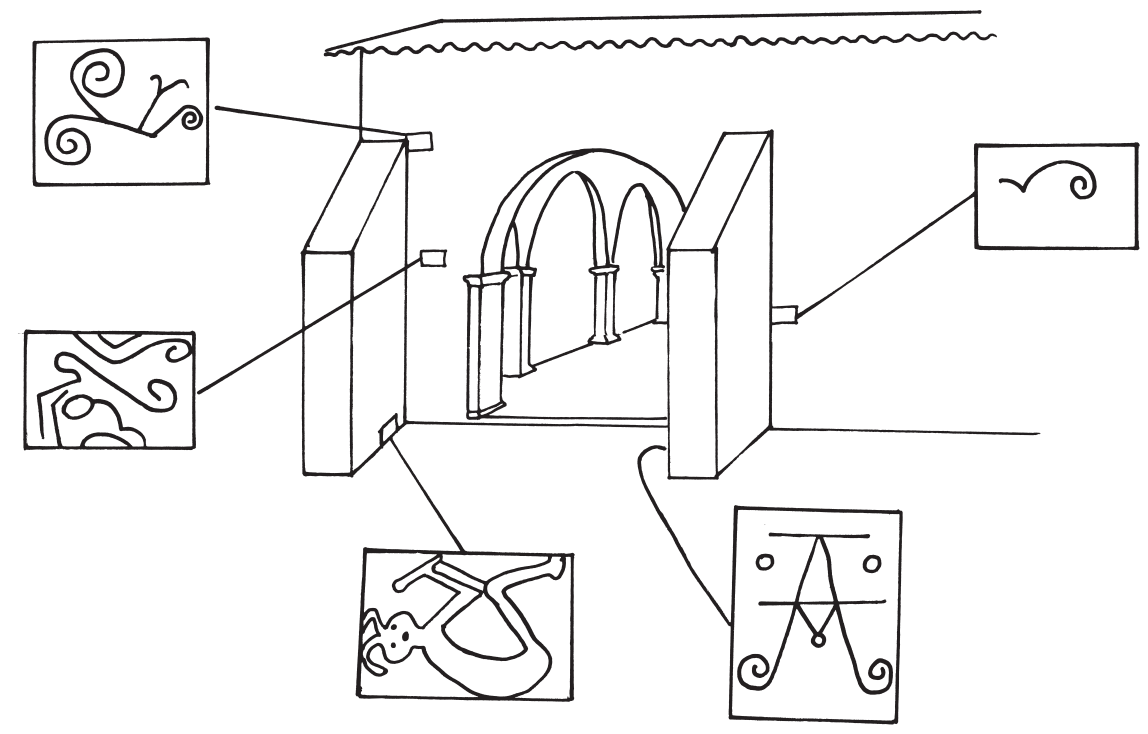

7. Capilla de hospital del convento de San Francisco, Tzintzuntzan. Costado poniente, con la indicación de los janamus decorados que ahí se encuentran, entre ellos el Flautista y la letra "A". Dibujo: V. H.

reúso de los janamus podría estar relacionada con la participación especial que tuvieron los indígenas en los hospitales y sus capillas. A la vez cabe pensar que la población nativa, su elite dirigente y los mismos trabajadores de la construcción emplearon de modo intencional las piedras con las imágenes antiguas que les eran propias y significativas, tal vez incluso sagradas. Recordemos que los janamus formaban parte de la principal arquitectura ceremonial de Tzintzuntzan, en particular de las yácatas-templos dedicados a Curicaueri, el dios más importante del panteón tarasco.

En la capilla de hospital mi percepción de intencionalidad se sustenta no sólo en la cantidad de janamus decorados ahí presentes, sino también en las imágenes que tienen y en su colocación específica. En este sentido conviene dirigir la atención a dos de las losas que se encuentran en el costado poniente de la capilla (fig. 7).

En la cara norte del contrafuerte suroeste, colindando con el piso, hay un janamu grabado con una letra A decorada con líneas rectas, espirales y círculos pequeños. El motivo es claramente poshispánico; debido a ello y a que, en com- 
paración con el resto de las imágenes, el grabado es más superficial y la piedra está menos deteriorada, es oportuno considerarlo novohispano. Concuerdo con Pablo Escalante cuando sugiere que pudiera remitir directamente a una persona o grupo purépecha, quizá una cofradía, a cargo del cuidado de la capilla de hospital. ${ }^{16}$

Justo frente a este motivo, en la cara sur del contrafuerte noroeste, se ve un janamu con una imagen antropomorfa en bajorrelieve. He identificado esta figura sentada, encorvada, con apéndices en la cabeza, que sostiene un objeto alargado cerca de la boca, como un "Flautista", en relación con el afamado personaje de las culturas indígenas del suroeste de Estados Unidos. La figura parece cortada en los apéndices de la cabeza y en los pies. El tipo de diseño, la técnica de manufactura y el estado físico de la piedra permiten atribuir su manufactura al periodo prehispánico.

La ubicación de los dos janamus denota una relación estrecha y explícita entre los dos diseños grabados, uno virreinal y el otro antiguo. De modo intrínseco se advierte el vínculo entre estas formas y sus realizadores; quizá uno de los sentidos fue manifestar la importancia del Flautista y la vigencia de la memoria histórica ligada a él. Tales asociaciones aportan indicios sobre la dimensión cultural de los petrograbados de Tzintzuntzan. Para abordar el asunto, en el apartado siguiente se atiende el motivo antropomorfo recién mencionado.

\section{El Flautista de Tzintzuntzan}

Entre los indios pueblo del suroeste de Estados Unidos (Arizona, Nuevo México, Utah y Colorado) el Flautista es un personaje característico desde el periodo antiguo y hasta el contemporáneo. Su presencia en Michoacán, un territorio a miles de kilómetros de distancia de dicha región, se explica dentro del marco de la larga historia de la cultura purépecha y los viajes que emprendieron grupos de esta etnia hacia el norte de Mesoamérica.

Estudios arqueológicos recientes han remontado en el tiempo los antecedentes del pueblo purépecha en relación con la cultura de Chupícuaro ( $c a .400$ a.C.-Ioo d.C.), cuya ocupación abarca un área colindante de Guanajuato y Michoacán; la historia continúa en las fases siguientes: Morales, de Guanajuato (Ioo a.C.-Ioo d.C.), Queréndaro y Loma Alta, de Michoacán (I5O a.C.-550 d.C.). 
A partir de 550 d.C. se advierte que de un área del centro-norte michoacano, grupos purépechas migraron al Norte y establecieron relaciones con la cultura chalchihuiteña de Zacatecas y Durango, y la hohokam de Arizona. Luego, de modo temporal y progresivo en un movimiento de norte a sur, hacia los años 750 y 900 respectivamente, se distingue en el suroeste de Guanajuato y en el mismo centro-norte de Michaocán el regreso de los que antes habían partido; este grupo purépecha por medio de conquistas y alianzas se impuso a las poblaciones ahí asentadas hasta llegar a la cuenca de Pátzcuaro y logró conformar hacia el 1350 el Estado tarasco. ${ }^{17}$

Joroba, falo y flauta son los rasgos más distintivos del Flautista en el suroeste estadounidense (fig. 8a). Como se ve, el de Tzintzuntzan no presenta falo y no toca directamente con la boca el objeto que toma en sus manos (fig. 8c), aunque sí cuenta con otras características típicas: la desnudez, el cuerpo encorvado, el objeto que lleva es similar a una flauta y los apéndices que suelen verse en la cabeza de este personaje, en el cual de modo común se conjuga la apariencia de insecto y humano. Aunado a ello, es interesante que en el arte hohokam, en Arizona, el Flautista usualmente es asexuado y la joroba no está definida (fig. 8b). ${ }^{18}$ Conviene agregar que en las obras donde suele encontrarse dicha imagen hay una amplia variedad formal. En dichas circunstancias, el de Tzintzuntzan puede integrarse dentro del repertorio de sus representaciones.

De manera paralela a su diversidad visual, cabe resaltar que la figuración del Flautista abarca una gran extensión temporal, espacial y material, que incluye cerámica, murales, kachinas y arte rupestre del suroeste estadounidense. A veces el Flautista es pequeño y sumamente esquemático, otras, de grandes dimensiones y con atributos distintos. Su apariencia suele ser humana, pero de igual modo aparece como insecto. Puede estar sentado, recostado, de pie, caminando o bailando. Muestra actitudes diferentes, así esté aislado, acompañado de uno o varios flautistas más, o asociado con otras figuras y en escenas complicadas. Acorde con sus rasgos específicos y los contextos donde se encuentra visual

17. Patricia Carot, "Arqueología de Michoacán: nuevas aportaciones a la historia purépecha”, en Beatriz Braniff (coord.), Introducción a la arqueología del Occidente de México, México, Instituto Nacional de Antropología e Historia/Universidad de Colima, 2004, pp. 443-474; en "La larga historia purépecha", Marie-Areti Hers (coord.), Miradas renovadas al Occidente de México, México, Universidad Nacional Autónoma de México-Instituto de Investigaciones Estéticas (en preparación).

I8. Dennis Slifer y James Duffield, Kokopelli, Flute Player Images in Rock Art, Santa Fe, Ancient City Press, 1994, p. 30. 


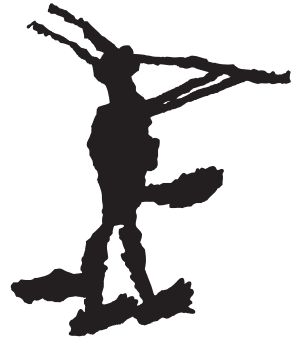

a)

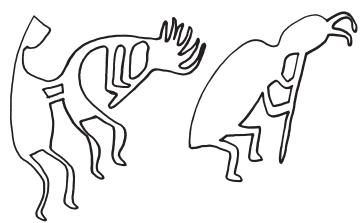

b)

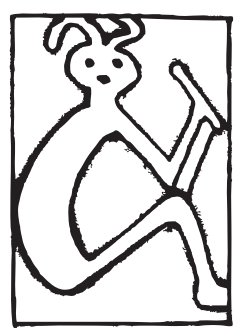

c)

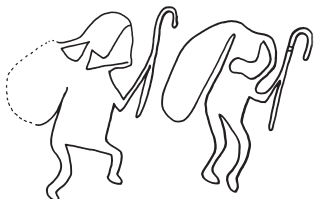

d)

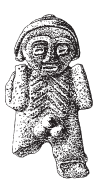

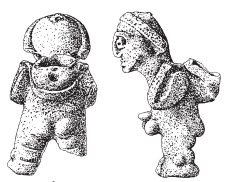

e)

8. a) Flautista, Sand Island, río San Juan, Utah, Estados Unidos; b) flautistas pintados en cerámica hohokam, Snaketown, Arizona, Estados Unidos; c) Flautista, Tzintzuntzan, Michoacán, México; d) diseños de cargadores de canastas en cerámica hohokam, sur de Arizona, Estados Unidos; e) escultura en piedra de un hombre desnudo, itifálico, cargando un recipiente con mecapal, Loma Alta, Michoacán, México.*

o literalmente (en los mitos e historia oral), entre los indígenas del suroeste el Flautista es símbolo de fertilidad, viajes y comercio; es un sacerdote de la lluvia, cazador mágico y seductor de doncellas, con marcada connotación sexual. ${ }^{19}$

$\mathrm{Al}$ margen de su amplio simbolismo, uno de los significados del Flautista de Tzintzuntzan remite a la figura del migrante.

La imagen del Flautista ha sido registrada también en Mesoamérica en expresiones de arte rupestre de Durango, Zacatecas y Jalisco, en sitios pertenecientes a la cultura chalchihuiteña. De acuerdo con Marie-Areti Hers, se han encontrado dos decenas en sus muy diversos modos de representación. Su presencia

19. Ibidem; Ekkehart Malotki, Kokopelli, the Making of an Icon, Lincoln, The University of Nebraska Press, 2000.

* Dibujos, V. H., basados en a) Jerry J. Brody, Los anasazi. La civilización de los antiguos indios pueblo, Barcelona, Lunwerg, 1990, fig. 25; b y d) Dennis Slifer y James Duffield, Kokopelli, Flute Player Images in Rock Art, Santa Fe, Ancient City Press, 1994, figs. 25-26 y fig. 20; e) Patricia Carot, "Arqueología de Michoacán: nuevas aportaciones a la historia purépecha", en Beatriz Braniff (coord.), Introducción a la arqueología del Occidente de México, México, Instituto Nacional de Antropología e Historia/Universidad de Colima, 2004, fig. 20. 
inicial se sitúa entre el 600 y el 850-900 d.C. y pudo ser casi contemporánea a su aparición en el suroeste, donde se plasmó aproximadamente desde el año $500 .{ }^{20}$ Entre investigadores estadounidenses es común reconocer un origen mesoamericano del Flautista a través de la figura de los comerciantes que recorrían largas distancias, de sur a norte, llevando la mercancía en sacos o sobre sus espaldas (fig. 8d). ${ }^{2 \mathrm{I}}$ En este sentido llama la atención una de las esculturas de piedra encontradas en Loma Alta, Michoacán, fechada entre 250 y 550 de nuestra era: es un cargador desnudo, con los atributos sexuales muy marcados, que sostiene un bulto a la espalda por medio de mecapal (fig. 8e). ${ }^{22}$

Algunos estudios identificaban ya en el desarrollo chalchihuiteño una clara compenetración entre Mesoamérica y el suroeste. ${ }^{23}$ El descubrimiento del Flautista en Tzintzuntzan confirma esta cercanía cultural y el retorno a Michoacán de los grupos purépechas, quienes trajeron consigo un novedoso bagaje norteño.

\section{Consideraciones finales}

En el presente trabajo se expuso un ejemplo de reutilización de elementos arquitectónicos antiguos en construcciones novohispanas. Se propuso dar a conocer que los janamus grabados son un ejemplo destacado del arte indígena en el transcurso de dos etapas: la prehispánica y la virreinal en Michoacán.

Sin duda muchos sucesos ocurrieron al paso de cinco siglos, desde finales de la década de 1570 , en la cual se inició la edificación definitiva del convento franciscano de Tzintzuntzan, hasta la actualidad, cuando se mantiene como un espacio vivo para el culto católico. Pese a las dificultades para saber si las piedras registradas estaban a la vista durante el periodo colonial, distingo elementos y circunstancias que me llevan a pensar que sus realizadores les dieron un empleo meditado.

20. Marie-Areti Hers, "La música amorosa de Kokopelli y el erotismo sagrado en los confines mesoamericanos", en Arnulfo Herrera (comp.), XXIII Coloquio Internacional de Historia del Arte. Amor y desamor en las artes, México, Universidad Nacional Autónoma de México-Instituto de Investigaciones Estéticas, 200I, pp. 293-336.

2I. Slifer y Duffield, op. cit., p. 7 .

22. Carot, "Arqueología de Michoacán...", op. cit., fig. sa.

23. Véanse Hers, "La música amorosa...", op. cit., y "Los toltecas y los caminos del lejano Noroeste", en Guadalupe Mastache (ed.), Tula y el mundo tolteca, México, Instituto Nacional de Antropología e Historia (en prensa). 
Principalmente considero dicha intencionalidad ligada a los tarascos, pero también reconozco que pudieron contar con la aprobación de los frailes franciscanos, poseedores de un espíritu humanista y cercanos a las tradiciones nativas como parte de sus tareas evangelizadoras. En un orden general de ideas es menester apuntar que aun cuando los diversos pueblos de Michoacán estuvieron sometidos a corregidores y alcaldes españoles, contaron con sus autoridades indígenas propias, de modo que la elite purépecha se mantuvo en el gobierno de la provincia michoacana hasta $1696 .^{24}$

A reserva de la carencia de una indagación extensa entre las culturas mesoamericanas, tengo la impresión de que las losas antiguas que tienen imágenes figuradas no fueron empleadas de modo común en la arquitectura colonial con la finalidad de que pudieran estar expuestas. En este sentido los janamus decorados de Tzintzuntzan tienen un carácter peculiar, pues en los edificios del convento fueron empotrados en las paredes. Este hecho se diferencia de lo que sí fue una práctica frecuente en las acciones de conquista: colocar las obras de los vencidos en los cimientos de las construcciones para denotar el poderío de los triunfadores. Es muy probable que este reúso particular de los janamus haya sido facilitado por la funcionalidad original de las piedras, es decir, como revestimiento arquitectónico. Se reafirma así cierta continuidad de la tradición prehispánica, al perdurar un estilo constructivo y ornamental.

Finalmente, cabe apuntar que en el origen de este trabajo está el descubrimiento que realicé del Flautista, un motivo plasmado en uno de los janamus, nunca antes referido en algún medio y que nos remite a la legendaria historia de los purépechas y a la antigua tradición de las migraciones hacia el norte de México desde Michoacán. \$

24. En ese año falleció el gobernador Constantino Bravo Huitzimengari II, último descendiente del cazonci o rey Zinzincha Tangaxoan. Cfr. Delfina López Sarralangue, La nobleza indígena de Pátzcuaro en la época virreinal, México, Universidad Nacional Autónoma de México-Instituto de Investigaciones Históricas (Serie Historia Novohispana, 29), 1965 y Rodrigo Martínez Baracs, Convivencia y utopía. El gobierno indio y español de la "ciudad de Mechuacan", I52I-I580, México, Fondo de Cultura Económica/Instituto Nacional de Antropología e Historia, 2005, pp. 156, 157 . 